\title{
REFLEXÕES SOBRE A FORMAÇÃO DO PROFESSOR DE MATEMÁTICA
}

\author{
Reflections about the mathmatics teacher's formation
}

Maria José de Freitas Mendes ${ }^{1}$

\section{RESUMO}

Este trabalho traz algumas reflexões sobre a formação do professor de Matemática, as quais fizeram parte da dissertação de mestrado da autora e que tinha como objetivo investigar o processo de formação do professor de Matemática. O foco do estudo incidiu sobre a contribuição da disciplina Prática de Ensino na formação do professor diante dos novos paradigmas de formação, com desenvolvimento profissional e como professor reflexivo. Essas reflexões, a partir do processo de aprender a ensinar e do significado de formar professor, analisam a crise e a reestruturação da formação do professor e concluem ser necessário, que nos cursos de licenciatura, seja dado um caráter mais prático à formação pedagógica, possibilitando ao futuro professor, desenvolver atitudes de autonomia, reflexão e investigação.

Palavras-chave: formação de professor; prática de ensino

\begin{abstract}
This paper brings some reflections about the formation of the math teacher that made part of my marsters paper and that aimed to investigate the process of formation of the math teacher. The focus of this study incided at the contributions of teaching practice in the teacher's formation above the new paradigms of formation, as a professional development and as a reflexive teacher. These reflections, from the learning and teaching process and from the meaning of form a teacher analyse the crisis and the reestruturation of the teacher's formation and conclude being necessary that in the graduation courses there's a character more practice to the pedagogical formation, making possible for the future teacher to develop atitudes of autonomy, reflexion and investigation.
\end{abstract}

Keywords: teacher's formation, teaching practice.

\footnotetext{
${ }^{1}$ Doutora em Educação pela Universidade Federal do Rio Grande do Norte, Brasil(2010). Professora associada da Universidade Federal do Pará, Brasil

AMAZÔNIA - Revista de Educação em Ciências e Matemáticas V.6 - n. 11 - jul. 2009/dez. 2009, V. 6 - n. 12 - jan 2010/dez. 2010
} 


\section{INTRODUÇÃO}

Nas últimas décadas, os especialistas da educação têm tentado racionalizar o ensino, procurando controlar a priori os fatores aleatórios e imprevisíveis do ato educativo, apartando o cotidiano pedagógico de todas as práticas, de todos os tempos, que não contribuem para o trabalho escolar propriamente dito (PERRENOUD, 1988).

Entretanto, não é possível reduzir a vida escolar às dimensões racionais, os atores da educação têm características pessoais distintas e por isso reagem de maneira diversa a cada ação e reflexão.

O professor ao construir sua identidade profissional, apropria-se de sua história pessoal que é composta de lembranças marcantes, as quais muitas vezes foram determinantes em suas escolhas. Essa identidade profissional, que, de forma muito feliz, Nóvoa (1995) caracterizou como um lugar de lutas e de conflitos, um espaço de construção de maneiras de ser e de estar na profissão, sendo portanto mais adequado falar de processo identitário, realça como cada um se sente e se diz professor. Pois, ao longo desse processo identitário, é que o professor adere a princípios e valores, adota maneiras de agir e decidir, e desenvolve o pensamento reflexivo capaz de gerar mudanças em sua ação pedagógica.

Nessas reflexões, pretendo confirmar essa concepção de construção de identidade profissional, com base na minha trajetória pessoal e profissional, e na pesquisa realizada com alunos da disciplina Prática de Ensino do Curso de Licenciatura em Matemática da Universidade Federal do Pará.

\section{O PROCESSO DE APRENDER A ENSINAR}

Camargo (1998), em suas pesquisas, mostra que situações vivenciadas como alunos são de forte influência no trabalho do professor em sala de aula, "porque correspondem a experiências reiteradas relativas ao ensino, à aprendizagem, à avaliação, à relação professor-aluno, ao papel do professor e do aluno em aula (...)" (CAMARGO,1998).

Autores como Darsie \& Carvalho (1998) também defendem a importância das experiências e conhecimentos trazidos pelos alunos-professores, ao iniciarem o curso de formação inicial. Compartilham da ideia de Feinman-Nenser e Buchmann (1987) de que,

o processo de aprender a ensinar começa muito antes dos alunos frequentarem os cursos de formação de professores; por isso temos que ter em conta as ideias anteriores e as regras que os alunos aliam à experiência, e devemos ajudá-los a exteriorizá-las e elaborá-las segundo concepções mais apropriadas (p.62).

E concluem: a formação inicial deverá ser capaz de levar os alunos-professores a exteriorizarem suas concepções, conhecimentos e experiências anteriores e, fundamentalmente, levá-los a refletir sobre estas com o objetivo de analisá-las, revê-las e reelaborá-las, de acordo com concepções, contextos epistemológicos, didáticos e ideológicos mais apropriados (DARSIE \& CARVALHO,1998).

Nessa perspectiva, é importante a experiência de, enquanto estudante, já atuar em sala de aula, o que hoje percebo não acontece com tanta frequência com os alunos da licenciatura. Este fato impõe a necessidade de que a prática de ensino e o estágio supervisionado sejam 
ministrados com uma conotação diferente da habitual, como aconteceu nas turmas que acompanhei em 2002, para a realização da pesquisa de minha dissertação de mestrado, a qual tinha por objetivo analisar as relações e as interações que se estabelecem no cotidiano escolar, e experienciar reflexivamente atividades e situações docentes nas escolas, tais como: monitorias, atendimento complementar a alunos com dificuldades em matemática, substituição do professor com o qual estagiava, sempre na tentativa de formar um profissional diferenciado.

Como lembra Nascimento (2000, p.36): “(...) o professor não se torna qualificado apenas devido à escolarização obrigatória, mas se faz qualificado no curso e em função do que, concretamente, é capaz de realizar no cotidiano da sua sala da aula e na escola”.

Até porque "o conceito de formação, que o conhecimento escolar legitima, está em permanente elaboração, devendo ser analisado em função da realidade social que este mesmo conhecimento escolar se propõe legitimar"(NASCIMENTO, 2000, p.35).

De acordo com Brzezinski (1995:12), o que define o profissional da educação são "as relações que ele estabelece na prática pedagógica e na prática social para satisfazer as necessidades para as quais foi formado".

Também Schön (1983) reconhece que uma das características da prática profissional é que ela envolve uma série de ações que as pessoas não sabem descrever com precisão, evidenciando a existência de um saber que é construído no próprio fazer.

Isso nos leva a pensar que o saber-fazer do professor constitui os conhecimentos e capacidades que cada um utiliza na sua prática (experiência) ou, ainda, constitui a sabedoria acumulada por meio da sua prática pessoal e coletiva (GOMES, 1995).

Hoje, é assim que entendo: é na prática, ou seja, na realização da atividade pedagógica que efetivamente compreendemos e construímos os saberes da profissão docente.

Para Gonçalves (2000:17), "a formação inicial deveria se configurar como uma formação para o docente se desenvolver profissionalmente".

E continua, citando Imbernón (1994a, p.11): "Unir a formação ao desenvolvimento da profissão (...) se trata de ver a formação como uma aprendizagem constante, levando esta ao desenvolvimento de atividades profissionais e à prática profissional a partir da formação inicial".

É preciso lembrar que a função do professor não se realiza apenas em sala de aula, o professor tem papel ativo na qualidade do ensino, na adequação e construção do currículo (IMBERNÓN,1994b). Para tanto, os membros de uma escola têm que dialogar para adquirir conhecimentos, conhecimentos estes gerados da prática e que contribuem para o aperfeiçoamento docente e a melhora escolar.

Além do mais, como nos lembra Clandinin (1993:1):

Quando nós ouvimos as histórias dos outros e contamos a nossa própria, nós aprendemos a dar sentido às nossas práticas pedagógicas como expressões do nosso conhecimento prático pessoal, que é o conhecimento experimental que estava incorporado em nós como pessoas e foi representado em nossas práticas pedagógicas e em nossas vidas. 
A participação, durante minha trajetória profissional, em diversos projetos da escola, se constituiu de momentos marcantes que contribuem para o meu desenvolvimento profissional, pela finalidade formativa que essas atividades encerram.

Essa concepção está muito próxima do que Garcia (1987) define como finalidade formativa do desenvolvimento profissional:

\begin{abstract}
Toda atividade que o professor em exercício realiza com uma finalidade formativa tanto de desenvolvimento profissional como pessoal, de modo individual ou em grupo - que o levem a uma realização mais eficaz de suas atuais tarefas ou o preparem para o desempenho de outras novas (GARCIA,1987:23).
\end{abstract}

Eu diria que nem precisa haver finalidade formativa para o professor. Desde que ele participe, envolvendo-se de fato, haverá "lucros" para seu desenvolvimento profissional e pessoal. E eu procurava, sim, me envolver e intervir, objetivando ajudar os alunos, refletir sobre minhas atitudes e também sobre a de meus alunos, fazendo com que houvesse um envolvimento emocional e afetivo, pois já entendia que o estabelecimento de uma relação de afetividade e de respeito com os alunos provoca a ação capaz de promover a educação. Freire (1996: 47) confirma o que quero dizer: "Às vezes, mal se imagina o que pode passar a representar na vida de um aluno um simples gesto do professor. O que pode um gesto aparentemente insignificante valer como força formadora ou como contribuição à do educando por si mesmo.

Nessa relação professora-alunos, um elemento nunca foi esquecido: o conhecimento da Matemática, que procurava fazer chegar aos alunos não apenas como conteúdo a ser adquirido, mas como conhecimento que habilita para inúmeras competências e, em especial, para o exercício da cidadania.

No magistério, como em qualquer outra atividade profissional, todas as experiências que temos servem de estímulo e enriquecem, não só o currículo, mas, principalmente, o nosso trabalho. Este enriquecimento será tanto mais fecundo, quanto mais a experiência se fizer acompanhar de uma reflexão sistemática, como afirma Infante et al. (1996, apud Gonçalves (2000),

\footnotetext{
No desenvolvimento do conhecimento profissional do professor se manifestam fenômenos de assimilação e acomodação. Neste processo, a reflexão é fundamental. De importância crucial, a reflexão permite ao professor inovar, evitando a rotina. Não é com a experiência que se aprende, mas com a reflexão sistemática sobre a experiência (p. 169).
}

De fato, as reflexões que tive oportunidade de fazer ao longo de toda essa participação em projetos envolvendo ou não o ensino, não só transformavam minhas crenças e concepções, como também me faziam refletir sobre as aulas que ministrava. Percebi que deveria tratar os conteúdos de forma a torná-los sócio-pedagogicamente relevantes e que era fundamental considerar os conhecimentos que os alunos possuem.

E, como nos diz Larrosa (1998), a formação tem a ver com experiência e experiência implica em formação; e a formação docente deve se processar por meio do envolvimento do docente em inúmeras e diversificadas experiências, e essas têm de ser vividas intensamente, de forma consciente e reflexiva pelo sujeito. 
Essas reflexões reforçaram em mim a concepção da necessidade de se formar adequadamente o professor de matemática para o ensino fundamental e médio, e para que isso possa vir a ocorrer, o curso de Licenciatura, por meio dos seus formadores de professores, não pode se limitar a valorizar somente os conteúdos específicos e alguns métodos de ensino, é necessário que faça a ligação entre os dois.

\section{O QUE SIGNIFICA FORMAR PROFESSOR?}

O conceito de formação de professores está cada vez mais identificado com o desenvolvimento permanente do professor, já que formação inicial e formação continuada não são mais do que dois momentos de um mesmo processo. Não se pode, pois, separar no tempo, uma aprendizagem teórica - associada indevidamente à formação inicial em uma instituição formadora - e uma aprendizagem prática de ensino, que se associa à atividade na escola.

Para Angulo Rasco (1993), professor é o indivíduo adulto que não somente assume, mas que realiza sua autonomia de julgamento, é capaz de expressar e defender as razões que sustentam suas decisões e ações sobre a formação dos cidadãos e cidadãs a seu cargo. Mas a autonomia, continua Angulo Rasco, não é algo estático que se adquire de uma vez para sempre, os profissionais têm a obrigação de estar continuamente enriquecendo e melhorando seu conhecimento, a autonomia está ligada à formação permanente de seu conhecimento, suas ações e decisões, da mesma maneira que, como assinala Stenhouse ${ }^{2}$, um ator ou uma atriz, vai enriquecendo ao longo de sua vida, com novos matizes e inflexões, a representação de um personagem.

Imbernón (1994b) afirma ser imprescindível na formação inicial a aquisição de algumas competências genéricas básicas: proporcionar ao professor cultura e estratégias que o capacitem para tomar suas próprias decisões, tendo fundamento para fazê-lo e capacitá-lo para atuar como investigador na aula, em processos de indagação sistemática, de reflexão sobre a prática que é analisada continuamente pelo professor e avaliada em comum com outros companheiros, e que possibilitem a investigação conjuntamente com os alunos na aquisição de conhecimentos.

A maioria dos estudos sobre formação do professor destaca a importância de desenvolver três componentes formativos: o científico, o psicopedagógico e o cultural. A eles, Imbernón (1994b) acrescenta um quarto componente: o prático, ou seja, a prática no exercício da profissão docente (reflexão sobre a própria prática), que no seu ponto de vista é fundamental, formando com os outros três os eixos fundamentais da formação, e que configuram uma determinada maneira de entender a profissão de ensinar.

A cada componente, Imbernón atribui uma clara orientação de finalidade. Assim, mediante o componente científico, o professor se prepara para ser um profissional que possui conhecimentos de disciplina, de área ou de áreas científicas que vai transmitir; por meio do componente psicopedagógico, o professor se prepara para ser um profissional que assume conhecimentos teóricos, práticos e tecnológicos das ciências da educação para sua aplicação no exercício docente; com o componente cultural, o professor se converte em um agente possuidor de uma cultura geral e de uma cultura específica de conhecimento do meio, onde exercerá a docência; e com estudo e reflexão sobre a prática docente nos centros de formação,

\footnotetext{
${ }^{2}$ Educador inglês, que, em 1970, fundou em East Anglia, o CARE (Center for Applied Research in Education Centro de Pesquisa Aplicada à Educação) e cujas ideias têm sido de grande importância para o movimento do professor como pesquisador, e da pesquisa como metodologia de ensino.
} 
o professor conhece a realidade educativa e experimenta e adequa as bases curriculares, determinadas pelos órgãos competentes, ao contexto onde exerce a profissão.

A formação do professor não tem por finalidade apenas que o aluno em formação aprenda, mas que aprenda a ensinar. A formação do profissional do ensino, como nos diz Guerra (1993), engloba múltiplas facetas que devem ser tratadas simultaneamente, evitando assim que alguma delas deixe de ser atendida e, consequentemente, que os problemas fiquem sem solução.

A formação do docente não se produz infundindo-lhe teorias sobre aprendizagem, educação, motivação, etc., para serem aplicadas de forma automática e indiscriminada aos contextos escolares. O caráter singular e mutante dos cenários, das culturas e dos contextos escolares, exige uma atuação profissional específica, um pensamento prático capaz de acomodar-se crítica, flexível e inteligentemente às peculiaridades de cada situação (GUERRA,1993).

Esse autor refere-se ainda a duas perspectivas na concepção do professor: a perspectiva técnica e a perspectiva prática.

A perspectiva técnica diz respeito à didática como ciência da aplicação. Nela, o professor é considerado como um técnico e o ensino como uma ciência aplicada, ou seja, o professor vai pôr em prática aquilo que os outros (teóricos, investigadores e administradores) elaboram; enquanto a perspectiva prática, na qual a didática é vista como uma ciência de indagação, concebe o professor como um profissional que reflete, diagnostica, investiga e atua de forma autônoma e crítica.

Essas perspectivas ajudam a entender a relação existente entre o profissional e o tipo de formação recebida por ele. A perspectiva técnica, por exemplo, não facilita a formação de profissionais reflexivos.

Nas últimas décadas, nas discussões sobre a formação do professor, a preparação para a prática reflexiva tem sido um tema sempre presente. Além dos esforços levados a efeito na América do Norte para tornar a investigação reflexiva o componente central da reforma educativa, encontramos esforços semelhantes em países como Reino Unido, Austrália, Noruega, Holanda, Espanha, Índia, Tailândia e Singapura (ZEICHNER,1993).

Esse movimento internacional para desenvolver o ensino e a formação do professor sob a bandeira da reflexão pode ser considerado como uma reação à visão do professor na perspectiva técnica de que nos fala Guerra (1993). Isso supõe o reconhecimento de que os professores são profissionais que têm de desempenhar papel ativo em seu trabalho, que também têm teorias e que são capazes de contribuir para a construção de uma base de conhecimentos sobre o ensino (ZEICHNER,1993).

Dewey $^{3}$ (apud ZEICHNER, 1993) define a ação reflexiva como a ação que supõe uma apreciação ativa, persistente e cuidadosa de toda crença ou prática, à luz dos fundamentos que a sustentam e das conseqüências às quais conduz. E considera necessárias três atitudes para a ação reflexiva: a abertura intelectual, a responsabilidade, e a sinceridade. A abertura intelectual refere-se ao desejo de atender a mais de um ponto de vista, a prestar mais atenção às possibilidades alternativas, e a reconhecer a possibilidade de erros até em nossas mais caras crenças; a atitude de responsabilidade supõe uma atenção cuidadosa das consequências às quais conduz a ação; e a sinceridade, reconhece que a abertura intelectual e a

\footnotetext{
3 John Dewey (1859-1952), filósofo, psicólogo e pedagogo norte-americano, que influenciou de forma determinante o pensamento pedagógico contemporâneo.
} 
responsabilidade devem constituir elementos fundamentais da vida do professor reflexivo, $\mathrm{e}$ implica que os professores se responsabilizem por sua própria aprendizagem.

Dewey (apud ZEICHNER,1993) distingue o ato reflexivo do ato de rotina. A reflexão implica intuição, emoção e paixão, não é algo que possa delimitar-se de maneira precisa, e ensinar-se como um conjunto de técnicas para uso dos professores.

A reflexão baseia-se na vontade, em atitudes de questionamento e de curiosidade, na busca da verdade e da justiça, sendo um processo ao mesmo tempo lógico e psicológico que une cognição e afetividade num ato próprio do ser humano (ALARCÃO, 1996).

A bibliografia atual sobre a prática reflexiva, tanto no ensino como em outras profissões, nos diz também que a reflexão é um processo que se leva a cabo antes e depois da ação (o que Donald Schön denomina reflexão sobre a ação) e, até certo ponto, também durante a ação, quando o professor mantém um diálogo reflexivo com as situações nas quais desenvolve sua atividade, enquadrando e resolvendo problemas sobre a caminhada. Schön o denomina reflexão na ação. Os mestres reflexivos examinam seu exercício docente tanto sobre como na ação (ZEICHNER,1993).

Para Schön (1983), o pensamento prático do profissional que, ao desenvolver suas atividades busca uma intervenção eficaz, é composto pelas dimensões: conhecimento na ação, reflexão na ação, reflexão sobre a ação e sobre a reflexão na ação, todas interdependentes e complementares.

O conhecimento na ação é aquele conhecimento que se manifesta no saber fazer. São saberes que interiorizamos e que muitas vezes não temos consciência de tê-los aprendido. É com esses saberes que primeiro transitamos profissionalmente. É um conhecimento que nos possibilita agir, que está colado a certo conhecimento "espontâneo, intuitivo, experimental" (NÓVOA, 1992).

Quando pensamos sobre o que fazemos ou quando pensamos enquanto fazemos algo, acontece a reflexão na ação.

\begin{abstract}
A reflexão na ação, considerada na prática profissional, tem na repetição um de seus elementos característicos. As situações que se repetem constituem o próprio âmbito da especialidade do profissional. Como produto de repetição o especialista desenvolve um repertório de expectativas, imagens e técnicas que formam uma base para suas decisões (PAIVA, 2003, p.51).
\end{abstract}

Não sendo um processo necessariamente pontual e rápido, a reflexão na ação pode, segundo Schön, converter o profissional em um "investigador no contexto da prática". "A reflexão na ação pode ser vista como um momento que gera mudanças, ou seja, com base nesta reflexão podemos encontrar novas pistas para soluções de problemas de aprendizagem" (CAMPOS \& PESSOA, 1998: 197).

A reflexão sobre a ação acontece quando enfrentamos uma situação nova, diferente, que para solucioná-la não valem as soluções já assimiladas; então, precisamos confrontá-la com o conhecimento acumulado e o conhecimento tácito, reconhecer sua singularidade, selecionar traços relevantes e extrair consequências a partir do conhecimento de casos anteriores e em comparação com eles. A reflexão sobre a ação possibilita a análise do conhecimento na ação e a reflexão na ação, introduzidos no contexto da própria prática (PAIVA, 2003).

O momento da reflexão sobre a reflexão na ação, 
(...) é marcado pela intenção de se refletir sobre a reflexão na ação, de maneira que se consiga produzir uma descrição verbal da reflexão na ação. É necessário ainda a capacidade de se refletir acerca da descrição resultante, podendo-se gerar modificações em ações futuras, ou seja: quando se reflete sobre a reflexão na ação, julgando e compreendendo o problema, podemos imaginar uma solução (CAMPOS \& PESSOA, 1998, p. 197-8).

Para Contreras (1997), a obra de Schön permite recuperar uma concepção da prática que não era valorizada por não ser produto da aplicação do conhecimento científicotécnico. O conhecimento tácito passa a ser considerado como conhecimento inteligente; a reflexão é entendida como um modo de conexão entre o conhecimento e a ação nos contextos práticos.

Esses conceitos de reflexão se opõem à racionalidade técnica que predomina no ensino, e tentam de algum modo superar a separação existente entre a teoria e a prática.

A partir de Schön, o uso do termo reflexão ganhou espaço na literatura sobre formação do professor, sendo citado por autores de diversas correntes pedagógicas.

Dentre esses autores, Zeichner (1993) focaliza a concepção tradicional de que a tarefa do professor consiste em aplicar em sua prática na escola a teoria produzida nas universidades e, sem desprezar estes conhecimentos, destaca que as estratégias docentes usadas em classe são teorias, tanto quanto as produzidas nas universidades.

Para Zeichner (1993):

O conceito de professor como profissional reflexivo reconhece a riqueza da habilidade que encerram as práticas dos bons professores.(...) A reflexão supõe também reconhecer que o processo de aprender a ensinar se prolonga durante toda a carreira docente do professor (p.45).

Zeichner concebe uma formação de professores que busca desenvolver a capacidade reflexiva do docente mediante um processo de pesquisa-ação sobre as origens, os objetivos e as consequiências de suas ações. Nessa concepção, a formação do professor tem como eixos norteadores, a formação cultural, o estudo crítico do contexto e a análise reflexiva da própria prática.

É essa também minha concepção de formação de professor. Entendo que é preciso criar uma tradição de pensamento e de reflexão e que a forma como essa análise reflexiva se realiza é de fundamental importância para o desenvolvimento profissional do professor. No exercício da profissão, o professor enfrenta constantemente desafios, que podem ser oriundos de sua própria educação, dos alunos, dos colegas, dos diretores, do governo e mesmo da família. Ao enfrentar esses desafios interagindo com o seu ambiente, o professor pode aprender, se modificar e se desenvolver profissionalmente. No processo de mudança e de desenvolvimento profissional, estão relacionados vários fatores que podem ser de ordem fisiológica, psicológica e social.

Em síntese, a prática educativa envolve experiências individuais, mexe com valores, visões de mundo e de sociedade, e refletir sobre ela contribui para a formação e para o desenvolvimento do profissional. 


\title{
A CRISE E A REESTRUTURAÇÃO DA FORMAÇÃO DO PROFESSOR
}

No século XIX, como consequência das revoluções francesa e industrial no desenvolvimento tecnológico, fez-se necessário repensar a Educação: era preciso transferir para a prática os ideais e as exigências advindos dessas revoluções.

No contexto sócio-político-econômico daquele século, novos rumos foram definidos, grandes massas da população se deslocaram para os centros urbanos em busca de trabalho em fábricas ou indústrias, onde a nova forma de produção fez desaparecer a velha forma de produção artesanal, a qual ainda se constituía como a única forma possível de Educação para as classes menos favorecidas de trabalhadores (MIORIM, 1998).

Com o avanço da ciência moderna e a geração de novas máquinas, as exigências do mundo do trabalho passaram a se multiplicar, provocando questionamentos sobre que tipo de Educação deveria ser apropriada para atender a essa nova classe de trabalhadores. Era preciso

\begin{abstract}
(...) preparar o operário para o uso adequado das novas máquinas, e isso só seria possível através da introdução do ensino de alguns elementos básicos da escrita e da matemática. Por outro lado, seria também preciso formar técnicos especializados, que através do conhecimento dos últimos avanços da ciência, pudessem melhorar ainda mais as técnicas de produção (MIORIM, 1998: 51).
\end{abstract}

Ao lado disso, era preciso também proporcionar o desenvolvimento de competências cognitivas e culturais necessárias para que os trabalhadores pudessem exercer seu papel na nova sociedade. Dessa forma, as classes populares começaram a usufruir do direito a um novo tipo de educação caracterizada pela renovação do ensino.

A ampliação do ensino que universaliza a educação passa a ser tema de discussões educacionais juntamente com a temática que evoca a relação educação-trabalho. Assim, tentava-se fazer desaparecer a separação flagrante que havia entre escola e trabalho, ou, em outras palavras, entre os "que pensam" e os "que fazem" (MIORIM, 1998).

No século XIX, as discussões provocaram a organização dos sistemas nacionais de ensino, os quais criaram novos tipos de escolas para atender a todas as camadas sociais.

De acordo com Miorim (1998:53):

\begin{abstract}
A importância cada vez mais acentuada das ciências para o desenvolvimento sóciopolítico-econômico acabou, entretanto, gerando pressões para modernizar o currículo das escolas (...) Voltou ao centro das atenções a antiga discussão sobre a melhor formação geral (...).
\end{abstract}

Observa-se que, ainda hoje, esse tema gera acalorados debates e continuados esforços da sociedade, no sentido de adequar a escola para o contexto da modernização. Nessa perspectiva, convém mencionar um exemplo de ação política-pública no âmbito educacional: o caso da regulamentação no Brasil das novas diretrizes do ensino a partir de 1996, cuja rubrica institui formalmente os PCNs, segundo os quais o novo currículo deve garantir a todos os alunos condições básicas para sua inserção no mundo do trabalho, para o exercício da cidadania e para a continuação da aprendizagem. 
Nos últimos anos, a preocupação com as novas e constantemente renovadas demandas da sociedade tecnológica têm provocado uma diversidade de iniciativas visando tanto à redução dos índices de analfabetismo como também à elevação das taxas de escolarização da população.

Essas iniciativas, ora ditadas pela consciência ou preocupação social das instituições civis ou governamentais, ora forçadas por pressões da mídia e de agências nacionais ou internacionais, são muitas vezes desenvolvidas em parceria com, ou coordenadas por setores e grupos sociais não diretamente vinculados à estrutura estatal, e levam governos, empresários, movimentos sociais, igrejas, ou organizações não-governamentais (ONGs) a investir, ou pressionar para que se invista, em projetos de Educação de Jovens e Adultos (EJA) (FONSECA, 2002).

Esses projetos são organizados com o propósito de preparar trabalhadores para um novo mercado de trabalho, consumidores para novos produtos e para novos padrões de consumo, e cidadãos para novas formas de exercer a cidadania.

Entretanto, nesses propósitos definidos para a Educação de Jovens e Adultos, há ainda muita expectativa sobre a adaptação desse indivíduo, excluído que foi do sistema escolar quando criança ou adolescente, à organização e valores de uma sociedade marcada por relações tão injustas, mas que de modo contrastante, procura conferir à EJA um novo sentido como o da reparação de um direito negado (FREIRE, 1989).

Considerando todos esses aspectos que configuram, por assim dizer, o perfil da educação nessas últimas décadas, é possível declarar que a formação do professor tem sido assunto de discussão entre profissionais e órgãos públicos ligados à educação em todo o mundo. Divergências à parte, uma opinião é unânime: a melhoria na formação do professor passa também por mudanças nos cursos de formação inicial.

Ultimamente, a formação e a atuação do professor têm sido objeto de preocupação constante, exigindo reflexões e análises em muitas teses de doutorado e dissertações de mestrado. A conclusão a que se chega é a de que há uma crise dos paradigmas em educação e se revela urgente a necessidade de mudanças no modelo dos cursos de Licenciatura. Essa mudança diz respeito não só às disciplinas curriculares e à forma como são ministradas, mas também em especial ao estágio curricular.

(...) considerando que as funções do estágio curricular, tais como vêm sendo desenvolvidas, parecem refletir um dos sinais mais visíveis da contradição que impera em nossa sociedade, o da dicotomia entre teoria e prática. (...) É difícil encontrar projetos pedagógicos coletivos nos cursos que formam professores, integrando uma teoria pedagógica à luz de problemas significativos encontrados nas escolas, campos naturais de estágios (PICONEZ, 1995:13).

É constante entre os especialistas em Educação/Formação de Professores, o dito: $O$ professor precisa mudar a sua maneira de ensinar. Mas, como mudar o que historicamente sempre fez parte de sua vida? A maneira de ensinar do professor tende a ser consequência da forma como o aluno viu seu professor agir desde seus estudos iniciais até à universidade.

Tradicionalmente, nos cursos de Licenciatura, há uma dicotomia entre conteúdo específico e conteúdo pedagógico. Os alunos, ao longo do curso, desenvolvem as disciplinas de conteúdos específicos de forma cada vez mais aprofundada. Apenas no final do curso, esses alunos entram em contato com disciplinas como didática e metodologia, sem que haja uma correlação entre estas e aquelas, isto é, o professor que ministra o conteúdo de sua 
disciplina não enfoca como o professor em formação trabalhará quando estiver em sala de aula com seus alunos.

Essa problemática reflete o pensamento comtiano, que diz:

É, pois, evidente que, depois de ter concebido, de maneira geral, o estudo da natureza como servindo de base racional à ação sobre ele, o espírito humano deva proceder a pesquisas teóricas, fazendo completamente abstração de toda consideração prática; (...) (COMTE,1978:24 ).

Da mesma forma que para Auguste Comte a pesquisa teórica deve fazer completa abstração a toda consideração prática, parece que nos cursos de formação de professores a lógica é a mesma. O que vemos é, na maioria das vezes, as disciplinas serem trabalhadas teoricamente, sem nenhuma relação com a prática do futuro professor.

Isso é confirmado quando, por ocasião da apresentação dos novos Projetos Pedagógicos dos Cursos de Licenciatura no V Seminário Pedagógico de Ensino de Ciências e Matemática (V SPECIM), realizado na UFPA em outubro de 2003, os alunos assim se manifestaram:

Estamos falando tanto em prática, mas como aplicá-la nas turmas de Ensino Fundamental e Médio (EFM) se o ensino da UFPA está voltado mais para a pesquisa? Como ensinar limite para turma de $8^{\mathrm{a}}$ série? (...)

Realmente o atual curso de Licenciatura em Matemática não prepara para atuar em sala de aula, sou fruto dessa formação. Essa nova proposta, teoricamente tem tudo para dar certo, e ajudará o [futuro] professor na sua prática.(...)

Hoje já se vislumbra uma luz nesse sentido, com a Resolução CNE/CP1/2002 ${ }^{4}$, que institui Diretrizes Curriculares Nacionais para os cursos de licenciatura, em seu Art. 12, parágrafos $1^{\circ}$ e $2^{\circ}$, estabelece que a prática nos cursos de formação não poderá ficar reduzida a um espaço isolado, desarticulado do restante do curso, mas deverá estar presente desde o início do curso e permear toda a formação do professor.

Entretanto, sem planejamento adequado, as tentativas de alterar o momento de entrada da prática de ensino, não têm surtido o efeito desejado, pois não há um acompanhamento do professor, de um orientador. O aluno é mandado para a escola, a prática de ensino começa antes, mas continua sem a articulação entre teoria-prática, indo de encontro ao que ressalta em seu Art. $1^{\circ}$ a Resolução $\mathrm{CNE} / \mathrm{CP} 2 / 2002^{5}$, que institui a duração e a carga horária dos cursos de licenciatura. Isso acontece, como nos mostra a literatura e as discussões em simpósios e congressos, em todos os lugares e em particular na UFPA.

Além disso, como nos lembra Giubilei (1993):

A despreocupação com os educandos maduros fica evidente nos cursos de formação de professores. As Licenciaturas, segundo a legislação pertinente, não cogitam do

\footnotetext{
${ }^{4}$ Resolução do Conselho Nacional de Educação, Conselho Pleno 1/2002. Diário Oficial da união. Brasília, 9 de abril de 2002. Seção 1,p.32. Republicada por ter saído com incorreção do original no D. O. U. de 4 de março de 2002. Seção 1, p.8.

${ }^{5}$ Resolução do Conselho Nacional de Educação, Conselho Pleno 2/2002. Diário Oficial da União, Brasília, 4 de março de 2002. Seção 1, p.8.
} 
aluno de mais idade, aos quais não se destinam os conteúdos curriculares apropriados. O tratamento dado não só pela Psicologia da Educação como pela Didática volta-se à compreensão da natureza da criança e do adolescente (p.4).

De fato, historicamente a educação de jovens e adultos tem sido considerada uma modalidade de ensino que não requer, de seus professores, nem estudo e nem especialização.

Entretanto, para desenvolver um ensino adequado a esta clientela é necessária uma formação inicial específica e geral consistente, assim como formação continuada.

Isso é confirmado pelos depoimentos dos professores de matemática da EJA

A universidade não prepara a gente para trabalhar em sala de aula, para a EJA
então..., ela [a universidade] dá o conteúdo, agora realmente a gente se prepara
quando vai para a sala de aula.(...) Na EJA o pessoal é muito carente, então
precisam que você converse, precisam que você repare neles (ADAUTO, Ent.2003).

Logo que me formei, no outro ano eu fiz especialização; quando eu entrei em sala de aula, comecei na EJA, eu estava cheia de idéias. Fazia especialização em Educação Matemática e colocava logo na prática, então me acostumei a ensinar diferente, mas pela universidade a gente tem muito pouco, a gente tem que correr atrás e ler muito (DORA, Ent.2003).

O professor em formação, quando chega ao final do curso, depara-se com a realidade, ou seja, aquela que será a sua em um futuro próximo: a sala de aula, a prática de ensino. $\mathrm{Na}$ disciplina Prática de Ensino, o professor em formação aprende-fazendo, (quando deveria estar aprendendo a fazer), em geral, quando já está atuando. Assim, muitas vezes assume a sala de aula como professor, despreparado para lidar com a dinâmica de uma escola e, em particular, com a sala de aula.

Na disciplina Prática de Ensino é fundamental a relação entre o estagiário e o professor regente da turma. O professor em exercício torna-se um professor-tutor, e aí está a dificuldade do trabalho na Prática de Ensino, pois encontramos diferentes situações, enquanto alguns professores agem como parceiros do processo de formação, como afirmam os alunos de Prática de Ensino:

\footnotetext{
A gente conversa muito, ele dá liberdade para eu fazer as coisas ali dentro do colégio, e também tudo o que ele faz pergunta se eu aprovo, algumas coisas até sobre o programa (...) É bom também o jeito dele, que tem muitos projetos, ele tenta fazer, procurar uma forma de ajudar esses alunos, ele é muito preocupado, também isso passa grande confiança para mim (Relatos, 2002).
}

outros entregam a turma para os estagiários sem nenhuma orientação, ou impedem o professor em formação de criar,

\footnotetext{
A gente nunca teve nenhuma aula para acompanhar, ela [a professora] entrega uma apostila e quer que a gente leve essa apostila o resto do ano (...) Aí a gente fica fazendo exercício, a turma fica chateada, diz que a gente é repetitivo, que a gente enrola(...) Eu dei por conta própria potenciação de fração e ela [a professora] ficou brava (...) (Relatos, 2002).
} 
Essa realidade impõe uma reflexão: Uma prática de ensino como esta resolve?

É impossível o professor de Prática de Ensino acompanhar todos os alunos, então, é fundamental o compromisso do professor regente da turma. Esse trabalho é uma parceria entre o professor regente, o estagiário e o professor da disciplina.

Os futuros professores, em sua maioria, atuam com orientação pedagógica deficitária. Em geral, diz-se do repasse de uma pedagogia anacrônica e inócua porque defasada e sem efeito produtivo. Em outras palavras, diz-se que da mesma forma com que receberam passivamente "instruções" por parte de seus professores, eles irão levá-las aos seus futuros alunos, os quais, por sua vez, irão recebê-las, por conseguinte, de forma passiva: ação extemporânea de caráter estático.

\section{CONSIDERAÇÕES FINAIS}

Cabe, pois, aos cursos de formação, às licenciaturas, o papel de formar docentes questionadores, investigadores, críticos, reflexivos, capazes de avaliar e traçar metas capazes de envolver a escola como um todo e interferir na estrutura do ensino.

Concordo plenamente com esse perfil de profissional, no entanto pergunto se isto é possível de ser feito com o tipo de formação - de inicial à pós-graduação - que tiveram os professores formadores das instituições de ensino que trabalham com a formação dos licenciados?

Gonçalves (2000) nos lembra que muito pouco se tem refletido sobre a formação e desenvolvimento profissional do formador de professores, que é fruto de uma cultura de formação profissional que acaba sendo preservada por nós formadores ao invés de tentar modificá-la. Essa mudança de cultura pressupõe reflexão, pesquisa, projetos e a formação de grupos de pesquisa, entre outros, buscando aprimorar a formação profissional tanto do professor do EFM quanto do formador de professores. Com base em sua pesquisa, conclui que no processo de formação profissional a experiência tem sido a principal responsável pelo desenvolvimento profissional do professor de matemática, em torno da qual devem orbitar os eixos fundamentais num processo de formação: formação matemática, formação geral e formação pedagógica.

Como bem acentua Soares (2001, p.93): "Formar professor não é apenas qualificá-lo em uma área específica, capacitá-lo teórica e metodologicamente para ensinar determinado conteúdo, mas é também formá-lo para enfrentar e construir a ação educativa escolar em sua totalidade".

Para tal, faz-se necessário estruturar currículos dirigidos à formação do professor por meio dos quais, entre outras coisas, seja dada ênfase aos conteúdos que o professor vai ensinar, proporcionando-lhe fundamentação conceitual desses conteúdos, e aos processos de raciocínio, levando-os a construir conhecimentos e a expressar com clareza seus pensamentos.

É imprescindível, também, resgatar o valor do saber docente, os saberes da experiência que emergem da realidade escolar e que funcionam como referência para o professor de Matemática, constituindo boa parte de sua cultura profissional. Nessa perspectiva, a lógica da racionalidade técnica dos cursos de formação, que não dá o devido valor à prática pedagógica do professor, deve ser superada para que passe a incorporar e 
valorizar os saberes que os professores possuem, de modo que sejam confrontados com a teoria (BICUDO,1999).

Paralelamente, é preciso implementar recursos bibliográficos e tecnológicos para que o ensino, a pesquisa e a extensão aconteçam dentro das instituições formadoras, concorrendo para o fortalecimento do processo de mudança no interior dessas instituições e para o aprimoramento e qualificação dos docentes formadores, através da educação continuada.

Afinal, ensinar a ser professor, além da aprendizagem das disciplinas específicas, implica também a aprendizagem dos aspectos de como ensinar e de como se inserir no espaço educativo escolar e na profissão docente (PONTE, 2000).

Portanto, a formação inicial deve levar em conta os conhecimentos, as crenças e as concepções que os formandos trazem sobre a atividade de ensino para, a partir desse conhecimento prévio, desenvolver práticas reflexivas e investigativas que impliquem autoformação e desenvolvimento pessoal e profissional. Desenvolver experiências de investigação sobre a prática durante a formação inicial é importante para que os futuros professores adquiram consciência de que, na sua profissão, o conhecimento é construído procurando corresponder às reais necessidades da escola e da comunidade.

$\mathrm{Na}$ formação inicial, deve ser dada ao formando oportunidade de trabalhar diversas metodologias de ensino e de aprendizagem, e também de avaliação, inclusive autoavaliação de seu desempenho, pois "o desejável seria o professor tomar conhecimento da diversidade de concepções, paradigmas e/ou ideologias para, então, criticamente, construir e assumir aquela perspectiva que melhor atenda às suas expectativas enquanto educador $\mathrm{e}$ pesquisador"(FIORENTINI,1995: 30).

Além disso, o professor precisa estar apto para cumprir sua missão, tanto intelectual quanto social, de forma a desenvolver em seus alunos a capacidade de lidar criticamente com a extraordinária gama de informações disponibilizadas pelas novas tecnologias, e de interpretar os fatos mais importantes sob uma visão humanista e universal que o conhecimento escolar legitima.

Também é possível supor que o aprendizado do fazer pedagógico aconteça de forma sistemática durante o curso, iniciando com uma fase de observação, pois é, de fato, importante que o professor em formação, no contato com o cotidiano escolar, aprenda a observar, a formular hipóteses e a selecionar instrumentos que o ajudarão a encontrar caminhos alternativos para a prática docente. Como bem enfatiza Ponte (2000, p.13): "A formação inicial deve proporcionar um conjunto coerente de saberes estruturados de uma forma progressiva, apoiados em atividades de campo e de iniciação à prática profissional, de modo a desenvolver as competências profissionais".

Por isso, a aproximação do formando com a escola deve acontecer de forma gradual, começando por atividades de observação e análise, e culminando com um estágio profissional, ou seja, com o exercício efetivo e pleno de funções docentes/educativas, sob uma supervisão adequada. A passagem por todas essas situações, até se atingir a situação de autonomia pedagógica, é fundamental na formação inicial de professores (PONTE, 2000).

Esta reformulação pode levar a um curso de formação por meio do qual - nas disciplinas de formação pedagógica ministradas - seja dada ênfase à integração entre os conceitos e processos matemáticos, a natureza da matemática e a aprendizagem da matemática, propiciando ao futuro educador matemático uma visão pedagógica do conteúdo, a qual se constitui a base necessária para pensar como se ensina matemática. Além disso, o aprendizado do fazer pedagógico passa a ocorrer ao longo do curso, com o aluno da licenciatura entrando, desde cedo, em contato com a realidade da sala de aula. 
Uma estrutura curricular desse porte possibilita melhor formação ao professor, pois para além da dimensão acadêmica, contempla uma componente que, sendo prática, é integradora de todos os saberes e decisiva para uma formação de qualidade, levando o futuro professor ao hábito de refletir cada ação como docente e, consequentemente, tornando-o capaz de teorizar e de reproduzir conhecimentos sobre suas práticas. Afinal, formar novos professores significa formar profissionais reflexivos, como já propunha Schön, na década de 90.

Hoje, com a estrutura vigente nos programas de formação, dificilmente um recémformado professor de Matemática estará preparado para os desafios da atual proposta curricular". E ao questionar: "O que é necessário para formar o futuro professor de Matemática?”, recorro à D’Ambrósio (1993) quando diz

\footnotetext{
O futuro professor de Matemática deve aprender novas ideias matemáticas de forma alternativa. O seu aprendizado de matérias como Cálculo, Álgebra, Probabilidade, Estatística e Geometria, no ensino superior, deve visar à investigação, à resolução de problemas, às aplicações, assim como uma análise histórica, sociológica e política do desenvolvimento da disciplina. Isso exige uma nova percepção por parte dos matemáticos de como se aprende Matemática, o que para muitos está além de suas preocupações (p.39).
}

O professor que queremos ver atuar deve pautar-se, entre outras coisas, pelo que pensa e nos indica D`Ambrósio (1993). Para tanto, o programa de formação do professor precisa romper com a dicotomia teoria-prática, trabalhando de forma integrada os saberes: matemático, psicopedagógico, cultural e prático, os quais, segundo Imbernón (1994b), representam os eixos fundamentais da formação.

Portanto, um curso que tem como meta formar professores, deve preparar seus alunos para entender os fenômenos educativos, de forma que sejam promovidas ações tais que contribuam para o aprimoramento do ensino. Além disso, deve sensibilizar os futuros professores para a necessidade de uma contínua atualização de conhecimentos, e fazer com que tomem consciência de que seu desenvolvimento profissional se dá por meio de projetos educativos nos quais teoria e prática possam ser combinadas com base nas reflexões realizadas e coordenadas tendo como referência o coletivo da escola.

\section{REFERÊNCIAS}

ALARCÃO, Isabel (org.) Formação reflexiva de professores: estratégias de supervisão. Lisboa: Editora Porto, 1996.

ÂNGULO RASCO, J. Félix. Qué profesorado queremos formar? Cuadernos de Pedagogia. Barcelona, n.220, p. 36-39, dic 1993.

BRZEZINSKI, I. Tendências na formação de professores. Mimeo: ANFOP. 1995.

BICUDO, M. Aparecida V. (Org.). Pesquisa em educação Matemática: concepções e perspectivas. S. Paulo: Editora UNESP, 1999.

\footnotetext{
${ }^{6}$ A proposta curricular sistematizada pela Lei 9394/96.
} 
CAMARGO, M. P. D'A.V. de. A reflexão de estudantes a professores da UNIMEP sobre sua formação profissional em matemática e ciências: subsídios para um novo projeto de Licenciatura. Piracicaba/ SP, 1998 (dissertação de mestrado).

CAMPOS, Silmara de \& PESSOA, Valda I. Fontenele. Discutindo a formação de professoras e professores com Donald Schön. In, GERALDI, C., FIORENTINI, D. e PEREIRA, E. (org) Cartografias do trabalho docente: professor(a)- pesquisador(a). Campinas, SP. Mercado das Letras: Associação de Leitura do Brasil, 1998.

CLANDININ, J.D. Teacher education as narrative inquiry. In: CLANDINI, J. D., DAVIES, A., HOGAN, P., KENNARD,B.(eds). Learning toteach, teaching to learn: stories of collaboration in teacher education. New York and London: Teachers College, Columbia University, 1993.

COMTE, Auguste. Discurso sobre o espírito positivo. São Paulo: Abril Cultural, 1978 (Coleção Os Pensadores).

CONTRERAS, J. La autonomia del professorado. Madri: Morata, 1997.

DARSIE, Marta Maria P.; CARVALHO, Ana Maria P. A reflexão na construção dos conhecimentos profissionais do professor de Matemática. Zetetiké, Campinas, n.10, p.57-76, jul./dez. 1998.

D’AMBRÓSIO, Beatriz S.- Formação de professores de matemática para o Século XXI: $O$ grande desafio. Pró-Posições, Campinas, n. 1 (10) p. 35-40,mar. 1993.

FIORENTINI, Dario. Alguns modos de ver e conceber o ensino da matemática no Brasil. Zetetiké, Campinas, n. 4, 1-37, nov. 1995

FONSECA, M. da Conceição F. R. Educação Matemática de jovens e adultos: especificidades, desafios, contribuições. Belo Horizonte: Autêntica, 2002, 113 p.

FREIRE, Paulo. Educação como prática da liberdade. Rio de Janeiro: Paz e Terra, 1989.

Pedagogia da autonomia: saberes necessários à prática educativa. 24. ed. S. Paulo: Paz e Terra, 1996, 165 p.

GARCIA J., E. Pensamento de los profesores sobre la evoluación. Una teoria práctica. Universidade de Sevilha: Tese doctoral inédita, 1987.

GIUBILEI, Sonia. Trabalhando com adultos, formando professores. Campinas, 1993, 200 p. Tese (Doutorado) Universidade Estadual de Campinas.

GOMES, A. P. O pensamento prático do professor: A formação do professor como profissional reflexivo. Lisboa: Dom Quixote, 1995.

GONÇALVES, Tadeu Oliver. Formação e desenvolvimento profissional de formadores: o caso dos professores de Matemática da UFPA. Campinas, 2000, 206 p. Tese de Doutorado em Educação Matemática. Faculdade de Educação, UNICAMP.

GUERRA, Miguel A. Santos. A formação inicial. Cuadernos de Pedagogia, Barcelona, n.220, p. 50-57, dic. 1993.

IMBERNÓN, Francisco. La formacion y el desarollo del profesorado. Hacia una nueva cultura profesional. Barcelona: Ed. Graó, 1994.

La formacion del professorado. Barcelona: Ed. Paidós, 1994.

LARROSA, J. La experiência de la lectura: Estudos sobre Literatura y Formación, Barcelona: Laertes S. A. ,1998. 
MIORIM, Maria Ângela. Introdução à história da educação matemática. São Paulo: Atual, 1998.

NASCIMENTO, Clara G. Sá G. A formação do professor e a prática pedagógica. Próposições, Campinas, vol.11, n.3 (33), p. 34-44, nov. 2000.

NÓVOA, António. Formação de professores e profissão docente. In: - Os professores e a sua formação. Lisboa: Dom Quixote, 1992.

Profissão professor. Porto; Porto Editora, 1995.

PAIVA, Edil V. de (org.). Pesquisando a formação de professores. Rio de Janeiro: DP\&A, 2003.

PERRENOUD, Philippe. La pédagogie de maîtrise, une pédagogie rationaliste? In: Assurer la réussite des apprentissages scolaires? [M. Huberman, ed., 1988

PICONEZ, S. C. B. Educação escolar de adultos: pós-alfabetizaçào. Campinas, 1995, 132p. Tese (Doutorado) . Faculdade de Educação, Universidade Estadual de Campinas.

PONTE, João Pedro da [et al.] Por uma formação inicial de professores de qualidade. Lisboa, abr. 2000, 18p. Documento de trabalho da Comissão ad hoc do CRUP para a formação de professores.

SCHÖN, Donald A. The reflective-practitioner: how professionals think in action. New York: Basic Books, 1983.

SOARES, Magda. As pesquisas nas áreas específicas influenciando o curso de formação de professores. In: ANDRÉ, Marli (org.). O papel da pesquisa na formação e na prática dos professores. Campinas, SP: Papirus, 2001- (Série Prática Pedagógica).

ZEICHNER, Kenneth M. El maestro como profissional reflexivo. Cuadernos de Pedagogia, Barcelona, n. 220. p. 44-49, dic. 1993. 